\title{
The Measurement of Aldosterone as a Parameter to Evaluate Portopulmonary Shunt
}

\author{
YOSHIKAZU KUROKAWA, YoICHIRO KOJIMA, \\ Koro SAKODA AND HACHINEN AKITA \\ Second Department of Surgery, Kagoshima University \\ School of Medicine, Kagoshima
}

\begin{abstract}
Synopsis
The effect of splenopneumopexy on hyperaldosteronism caused by constriction of the thoracic inferior vena cava was studied. In the experiments, the double isotope dilution derivative method of Brodie et al. (1967) have been used and found to be an adequate and reliable method for the study of aldosterone in peripheral plasma. Hyperaldosteronism following thoracic inferior vena caval constriction was significantly relieved by a portopulmonary shunt. Ascites was well controlled. Improvement of systemic and hepatic hemodynamics which allow aldosterone metabolism to proceed seems the most likely mechanism.

Our data support the clinical impression that splenopneumopexy is an effective procedure to control the ascites associated with portal hypertension, especially in the Budd-Chiari syndrome.
\end{abstract}

Simpson, Tait, and others isolated crystalline electrocortin in 1953. One year later, its structure was determined and the term aldosterone was coined. In 1955, Conn established the concepts of primary aldosteronism and secondary aldosteronism as a new clinical entity. Since then, extensive investigations have been reported on the regulation of secretion and metabolism of aldosterone. (Bartter et al., 1956; Llaurado and Woodruff, 1957; Kliman and Peterson, 1960; Blair-West et al., 1963; Davis et al., 1965; Orloff et al., 1965; Coghlan and Scoggins, 1967; Bayard et al., 1970; Ito et al., 1972)

In 1958, Akita devised hepatopneumopexy as a surgical treatment for ascites in patients with liver cirrhosis. This operation consists of direct fixation of the liver and lung and is designed to produce collateral communications thereby improving hepatic blood out-

Received for publication November 12, 1973. flow which is commonly blocked in liver cirrhosis. The procedure was the first attempt to produce a portopulmonary shunt. However the collateral communications produced by hepatopneumopexy were not always sufficient to alleviate portal hypertension and therefore splenopneumopexy which consists of direct fixation between the spleen and lung after partial removal of the left diaphragm was then used (Akita, 1967). This additional procedure produced a remarkable portopulmonary shunt. Extensive experimental and clinical investigations revealed that splenopneumopexy was an effective surgical procedure for portal hypertension, especially for Budd-Chiari syndrome (Akita et al., 1967; Akita et al., 1968).

As one of the important secondary aldosteronism, patients with liver cirrhosis and ascites are often found to have increased levels of plasma aldosterone (Wolff et al., 1965). Hyperaldosteronism has been reported to be an important factor in the production 
of ascites in liver disease. In this paper, the effect of splenopneumopexy on hyperaldosteronism caused by constriction of the thoracic inferior vena cava is studied. Measurements of aldosterone in peripheral plasma of dogs were performed using the double isotope dilution derivative method by Brodie et al. (1967).

\section{Materials and Methods}

\section{Experimental animals}

The animals in this study were adult male mongrel dogs averaging $10 \mathrm{~kg}$. All surgery was performed on dogs anesthetized with sodium thiopentobarbital $25 \mathrm{mg} / \mathrm{kg}$. Three experimental groups were studied: Group 1 consisted of normal dogs, Group 2 had constriction of the thoracic infericr vena cava, and Group 3 had constriction of the thoracic inferior vena cava four weeks after the splenopneumopexy. The dogs were kept in metabolic cages during the experiment and fed a dog food which contained 40-60 $\mathrm{mEq} \mathrm{Na}$ /day and $10-20 \mathrm{mEq} \mathrm{K} /$ day. Water was allowed ad libitum. Blood sample was collected about $60 \mathrm{~m} l$, from juglar veins in the standing position, at 11 a.m. on the 10th and 20th days after constriction of the thoracic inferior vena cava in Groups 2 and 3. The blood obtained from Group 1 served as a control. Immediately after collection, the blood was centrifuged to obtain plasma. The plasma was stored at $-20^{\circ} \mathrm{C}$ until required for assay. Each animal's girth and weight were measured prior to and intermittently throughout the course of the experiment.

\section{Labelled Steroids}

The $4-{ }^{14} \mathrm{C}$-aldosterone indicator (specific activity $56.7 \mathrm{mCi} / \mathrm{mmole}$, The Radiochemical Center, Amersham) was purified according to the method described in the original report (1967). The ${ }^{3} \mathrm{H}$-acetic anhydride (specific activity $500 \mathrm{mCi} / \mathrm{mmole}$, The Radiochemical Center, Amersham) was obtained periodically in $100 \mathrm{mCi}$ amounts as a $10 \%$ solution in anhydrous benzene. On the day of reaction, it was redistilled in vacuo at least 3 times immediately before use.

\section{Reagents}

Aldosterone 21-monoacetate and aldosterone 18, 21-diacetate were prepared by the method described originally (1967). They were diluted to convenient concentrations with ethanol and kept in a volumetric flask at $5^{\circ} \mathrm{C}$. They, also, were frequently tested for possible tritium contamination. Acetic anhydride (spectroquality, Nakarai Chemical Co.) was refluxed over $\mathrm{CaH}_{2}$ for $6 \mathrm{hr}$ and distilled through a fractionat-

\section{Experimental Group}
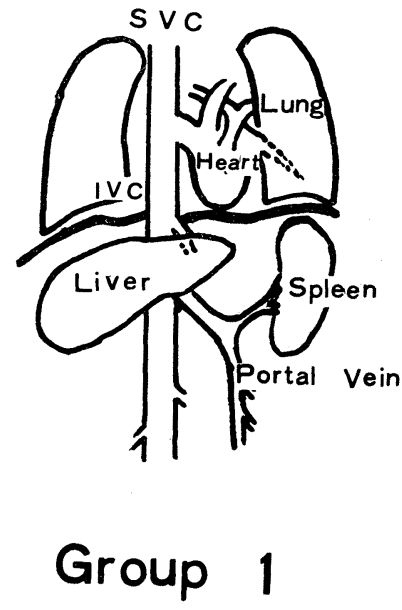

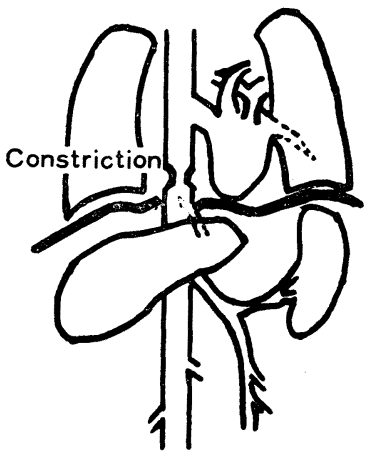

Group 2

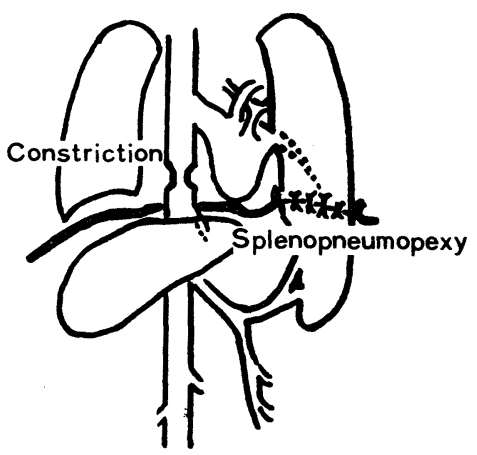

Group 3

Fig. 1. Experimental Group: Group 1 consisted of normal dogs, Group 2 had constriction of the thoracic inferior vena cava, and Group 3 had constriction of the thoracic inferior vena cava four weeks after the splenopneumopexy. 
ing column. The fraction boiling at $140^{\circ} \mathrm{C}$ was collected under the anhydrous condition. Pyridine (spectroquality, Nakarai Chemical Co.) was kept with an excess of $\mathrm{KOH}$ overnight at room temperature. After separation sodium wires were added to the roughly dried pyridine, and the completely anhydrous pyridine was obtained by the distillation from the sodium wires at $116^{\circ} \mathrm{C}$. These procedures were carried out immediately before use. Benzene (chromatographical grade, Nakarai Chemical Co.), also, was distilled at $80^{\circ} \mathrm{C}$ after addition of sodium wires. Methylene dichloride, cyclohexane, ethylacetate, acetone, methanol, ethanol, and toluene were obtained from commercial sources (specially prepared reagents, Nakarai Chemical Co.) and used without further purification. A solution of $0.22 \mathrm{M} \mathrm{HCl}, 0.054 \mathrm{M} \mathrm{KCl}$, and $0.0025 \mathrm{M}$ potassium acetate was used as the buffer of acid hydrolysis. For radioactivity assay, scintillator containing $4 \mathrm{~g}$ of 2.5 -diphenyloxazole (PPO) and $0.1 \mathrm{~g}$ of 1.4-bis-2-(5-phenyloxazolyl)-benzene (POPOP) in one liter of toluene containing $2 \%$ ethanol were used. Potassium free glass counting vials were purchased from Beckman Corp. Silica gel GF 254(Merck) was employed for thin layer chromatography and Whatman No. 2 for paper chromatography. Thin layers, $250 \mu$ in thickness, were prepared by spreading silica gel suspension on glass plates, $20 \times 20 \mathrm{~cm}$. After removal of the moisture in air, the plates were dried for $1 \mathrm{hr}$ at $110^{\circ} \mathrm{C}$.

\section{Methods}

Measurements of $\mathrm{Na}^{+}, \mathrm{K}^{+}, \mathrm{Cl}^{-}$, and protein in the plasma and the liver function test were carried out by routine methods in parallel with the measurement of aldosterone. The measurement of aldosterone in the plasma was carried out as follows: 1) Extraction: To $20 \mathrm{ml}$ dog plasma, $1 \mathrm{~m} \mu \mathrm{g}(353 \mathrm{dpm})$ or $2 \mathrm{~m} \mu \mathrm{g}$ $(706 \mathrm{dpm})$ of $4-{ }^{14} \mathrm{C}$-aldosterone $(56.7 \mathrm{mCi} / \mathrm{mmole})$ in $0.5 \mathrm{ml}$ ethanol was added as the indicator. To this was added $0.4 \mathrm{~m} l$ of $1.25 \mathrm{~N} \mathrm{NaOH}$ solution, and the mixture was extracted twice with $60 \mathrm{~m} /$ of ice cold methylene dichloride. The extract was washed in succession with $6 \mathrm{ml}$ of $0.1 \mathrm{M}$ acetic acid and 3 times with $3 \mathrm{ml}$ distilled water. After evaporation of methylene dichloride, the residue was dissolved in $5 \mathrm{ml}$ of $20 \%$ ethanol. This was partitioned against $10 \mathrm{ml}$ cyclohexane for the removal of contamination. The $20 \%$ ethanol solution was extracted twice again with $15 \mathrm{~m} l$ methylene dichloride. The extract was then washed 3 times with $3 \mathrm{ml}$ distilled water and evaporated to dryness. Residue was transferred to tubes with specially attached stoppers, and a few drops of ethanol were used to concentrate the extract into tip of the tube. The tubes were then dried in vacuo for at least $3 \mathrm{hr}$ prior to acetylation. 2) Acetylation: A mixture of $0.025 \mathrm{~m} l$ anhydrous pyridine and $0.01 \mathrm{ml}$
${ }^{3} \mathrm{H}$-acetic anhydride was added to each tube, and the tube was stoppered very tightly to prevent moisture. A hood was specially devised to keep thoroughly dry and used during this reaction. The acetylation was allowed to proceed at room temperature overnight. One half $\mathrm{m} l$ ethanol was then added to each tube and evaporated to dryness after $10 \mathrm{~min}$. The residue was dissolved in $0.1 \mathrm{~m} l$ ethanol, and $0.5 \mathrm{~m} l$ of the buffer solution was added to the solution for hydrolysis. After hydrolysis for $30 \mathrm{~min}$. at room temperature, the acid solution was diluted with $1 \mathrm{~m} l$ distilled water and extracted 3 times with $5 \mathrm{ml}$ methylene dichloride. The extract was washed in succession with $1.5 \mathrm{ml}$ sodium acetate solution $(19 \mathrm{mg} / \mathrm{ml})$ and $1 \mathrm{ml}$ of $1 / 50 \mathrm{~N}$ $\mathrm{Na}_{2} \mathrm{CO}_{3}$ solution, and 3 times with $1 \mathrm{~m} l$ distilled water. After the methylene dichloride was evaporated, aldosterone 21 -monoacetate $(5 \mu \mathrm{g})$ in a small amount of ethanol was added to the residue as a carrier. This was used as a sample for the first thin layer chromatography. 3) Purification by chromatography: a) First thin layer chromatography: A two dimensional thin layer chromatography procedure was carried out, in one direction with $5 \%$ methanol in chloroform and in other direction with $25 \%$ cyclohexane in ethylacetate. The $4-{ }^{14} \mathrm{C}$-aldosterone- ${ }^{3} \mathrm{H}$-monoacetate product was examined by X-ray film for radioautography to confirm the position of spot detected under the ultraviolet light. $\mathrm{Rf}$ values of the sample were 0.47 and 0.39 , respectively. For elution from thin layer chromatogram, the spot area was sucked up with a disposable Pasteur pipette plugged with glass wool, and the material was then eluted with $5 \mathrm{ml}$ acetone. After removal of acetone, the residue $\left(4-{ }^{14} \mathrm{C}\right.$-aldosterone${ }^{3} \mathrm{H}-21$-monoacetate) was acetylated with a mixture of $0.6 \mathrm{ml}$ anhydrous pyridine and $0.3 \mathrm{ml}$ of nonradioactive acetic anhydride at room temperature overnight. After evaporation to dryness, $0.5 \mathrm{~m} l$ ethanol was added to the dried residue, left $10 \mathrm{~min}$, and evaporated in vacuo. The labelled aldosterone 18, 21diacetate obtained was used as a sample for the second procedure. b) Second thin layer chromatography: A second purification by two dimensional thin layer chromatography was then carried out with the same solvent system as described above. $\mathrm{Rf}$ values of the sample were 0.79 in one direction and 0.39 in other direction. c) Paper chromatography: The dried eluate of the labelled aldosterone diacetate was prepared from the above chromatogram, and to this, aldosterone 18,21 -diacetate $(10 \mu \mathrm{g})$ was combined as carrier. The material was then chromatographed on paper in a solvent system of cyclohexane-benzenemethanol-water $(10: 4: 10: 2: \mathrm{V} / \mathrm{V})$ for $12 \mathrm{hr}$ at room temperature. The $\mathrm{Rf}$ value of aldosterone 18, 21diacetate was 0.69 . The blue dye $F_{11}$ was used as visible reference marker. The aldosterone 18, 21diacetate was eluted with ethanol and dried. The 
residue was chromatographed on paper in use of a reverse phase system. The paper was impregnated with a solvent (mesitylene-methanol-water, 3:2:1). The mobile phase was $66 \%$ methanol equilibrated with mesitylene. The chromatogram was allowed to run for $16 \mathrm{hr}$ at room temperature. The $\mathrm{Rf}$ value of aldosterone 18, 21-diacetate was 0.45 . Rhodamin B was used as a marker dye. The dried eluate of aldosterone 18, 21-diacetate was hydrolyzed in the buffer solution under the same condition as described before. The purification of aldosterone 21-monoacetate obtained was carried out by the paper chromatography in the Bush B2 system (toluene-Skelsolve C-methanol-water, 2: 1:4:1). After impregnation of the paper with a solution of methanol-water-ether $(25: 12: 63 \mathrm{~V} / \mathrm{V})$, the paper was allowed to dry for 3-5 min. until the ether had evaporated and then placed in the chromatograph tank for $10 \mathrm{~min}$., after which time the chromatogram was started and allowed to run for $3 \mathrm{hr}$ at room temperature. The $\mathrm{Rf}$ value of aldosterone 21-monoacetate was 0.24 . The sample eluted from the chromatogram was assayed for radioactivity. 4) Estimation of radioactivity. The final dried residues were transferred in toluene to vials containing $10 \mathrm{~m} l$ of scintillator and counted in a liquid scintillation spectrophotometer (LS-150, Beckman Instruments Inc.), two times, for $100 \mathrm{~min}$. The counters efficiencies were $60 \%$ for ${ }^{14} \mathrm{C}$ and $30 \%$ for ${ }^{3} \mathrm{H}$ under Gain 340, dual conditions. All samples were corrected for quenching background; ${ }^{3} \mathrm{H}$ determinations were corrected mathematically for ${ }^{14} \mathrm{C}$ contributions (about 10\%). 5) The amount of aldosterone $(\mathrm{m} \mu \mathrm{g})$ in plasma was calculated as described (1967).

\section{Results}

A number of studies were carried out to evaluate the reliability of the method.

Specificity: The nonspecific (water) blank of the method after establishment of the

Table 1. The concentration of aldosterone in peripheral plasma in Groups 1, 2 and 3.

$\mathrm{m} \mu \mathrm{g} / 100 \mathrm{~m} l$

\begin{tabular}{|c|c|c|c|c|c|c|c|}
\hline \multirow{2}{*}{ No. } & \multirow{2}{*}{ Group I } & \multirow{2}{*}{ No. } & \multicolumn{2}{|c|}{ Group II } & \multirow{2}{*}{ No. } & \multicolumn{2}{|c|}{ Group III } \\
\hline & & & 10 Days & 20 Days & & 10 Days & 20 Days \\
\hline 1 & 0.948 & 21 & 22.394 & 30.395 & 51 & 9.331 & 3,954 \\
\hline 2 & 0.996 & 22 & 19.273 & 24.094 & 54 & 11.621 & 8.634 \\
\hline 3 & 0.861 & 25 & 21.494 & 27.293 & 55 & 12.717 & 10.426 \\
\hline 4 & 0.429 & 26 & 18.649 & 22.285 & 57 & 6.396 & 3.791 \\
\hline 5 & 0.912 & 28 & 20.302 & 22.451 & 59 & 10.602 & 4.394 \\
\hline 6 & 0.908 & 30 & 19.192 & 25.332 & 61 & 10.809 & 4.110 \\
\hline & $07 \pm 0.085^{*}$ & & $\begin{array}{l}217 \\
1.468 \pm 0.599\end{array}$ & $\begin{array}{l}25.308 \\
\pm 3.118 \pm 1.273\end{array}$ & & $\begin{array}{l}10.246 \\
\pm 2.195 \pm 0.896\end{array}$ & $\begin{array}{l}5.885 \\
\pm 2.887 \pm 1.178\end{array}$ \\
\hline
\end{tabular}

* Mean \pm S.D. \pm S.E.

Table 2. Changes of liver function test in Groups 1, 2 and 3.

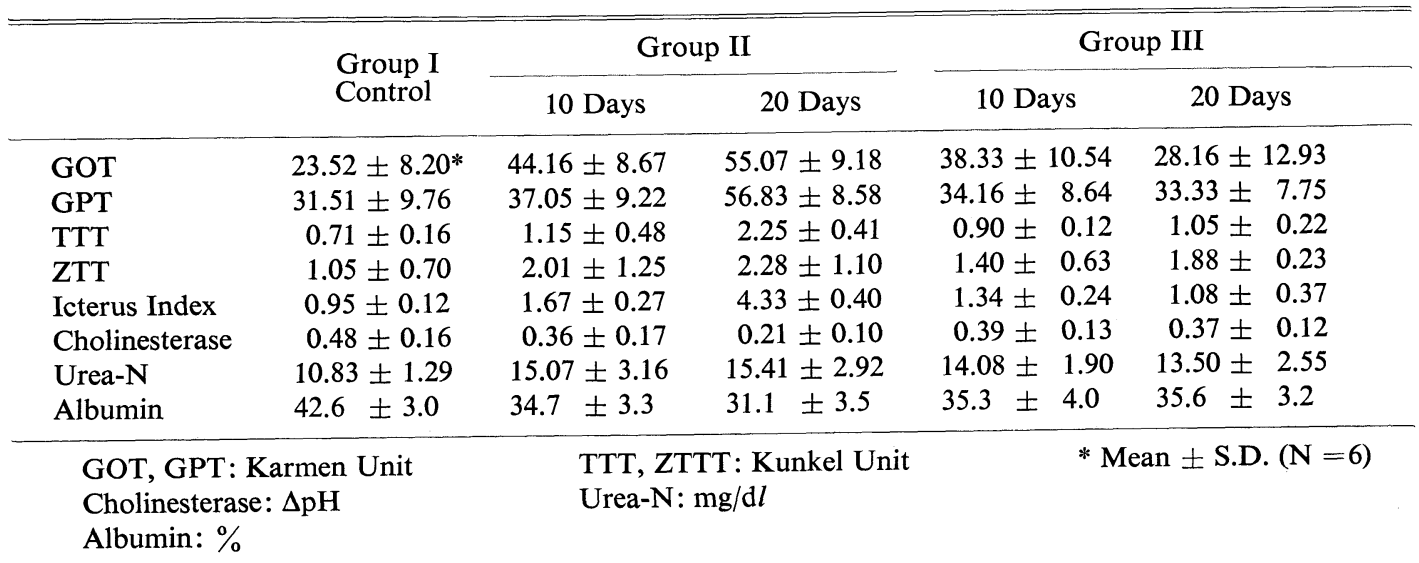


technique in our laboratories was $0.116 \pm$ 0.007 (SD), \pm 0.003 (SE) $\mathrm{m} \mu \mathrm{g} / 20 \mathrm{ml}(\mathrm{n}=7)$. The plasma samples from adrenalectomized dogs gave $0.155 \pm 0.001$ (SD) $\mathrm{m} \mu \mathrm{g} / 20 \mathrm{ml}$ $(\mathrm{n}=3)$. The ${ }^{3} \mathrm{H} /{ }^{14} \mathrm{C}$ ratio obtained after the final stage of the method was ranged 2.2 to 9.9.

Recovery: The mean recovery of $4-{ }^{14} \mathrm{C}$ -

PLAS:'A ELECTROLYTES ( $\mathrm{M} A, K, \mathrm{Cl}$ )

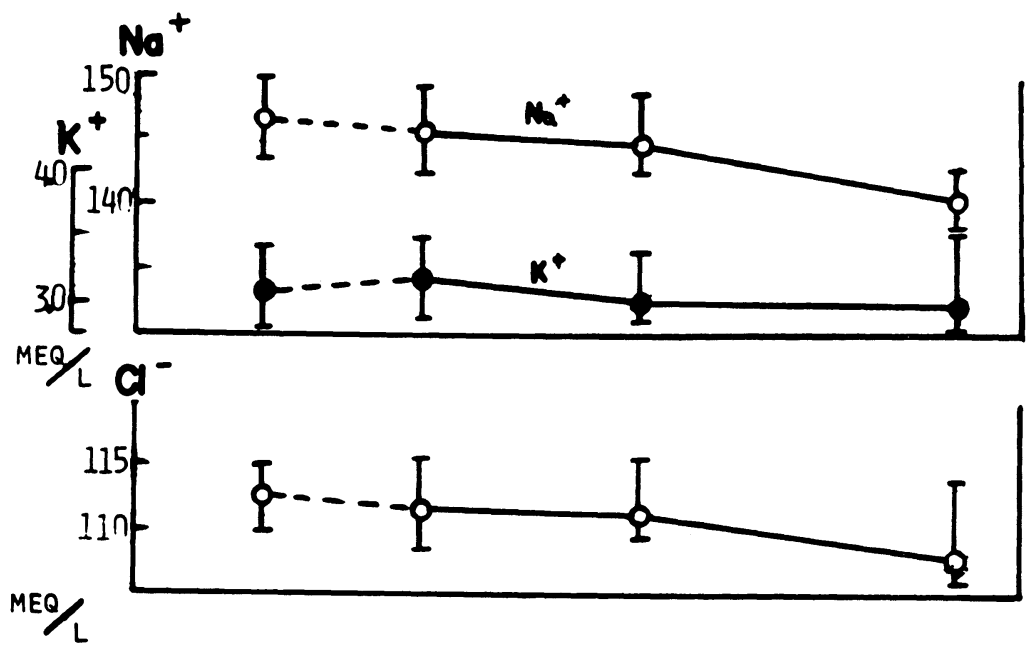

BODY WEIGHT AND ABDOMINAL GIRTH

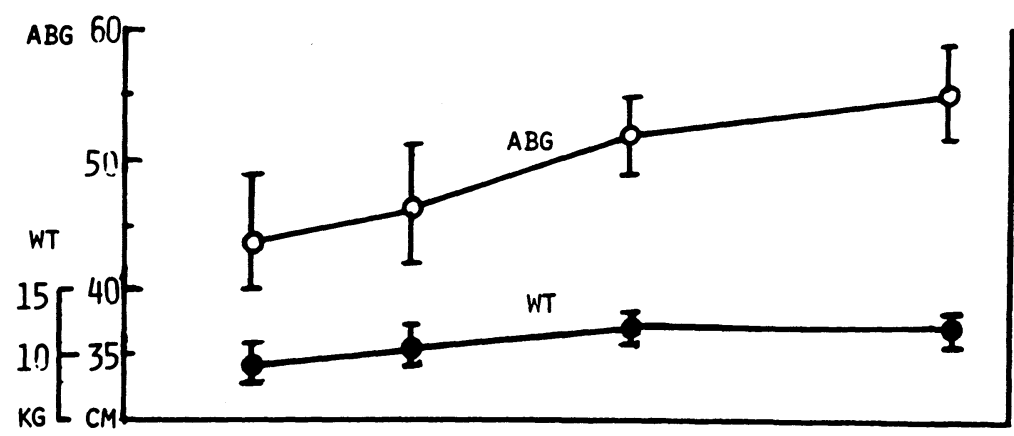

\section{ALDOSTERONE}

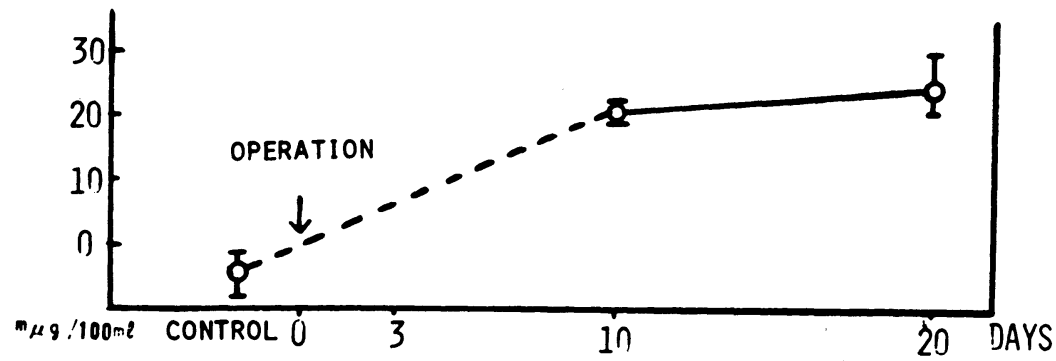

Fig. 2. Plasma electrolytes $\left(\mathrm{Na}^{+}, \mathrm{K}^{+}, \mathrm{Cl}^{-}\right)$, body weight, abdominal girth and aldosterone in Group 2. 
aldosterone added to plasma was $19.730 \pm$ $0.770(\mathrm{SD}), \pm 0.105(\mathrm{SE}) \%(\mathrm{n}=54)$.

Precision: Mean values for replicate estimates of the two plasma pools from operated dogs were $2.031 \pm 0.094(\mathrm{SD}), \pm 0.047$ (SE) $\mathrm{m} \mu \mathrm{g} / 20 \mathrm{~m} l \quad(\mathrm{n}=4), \quad 5.042 \pm 0.339$ (SD), \pm 0.170 (SE) $\mathrm{m} \mu \mathrm{g} / 20 \mathrm{~m} l(\mathrm{n}=4)$ respectivelly. Accuracy: The analysis of variance gave

PLASIA ELECTROLYTES ( $\mathrm{H}_{A}, \mathrm{~K}, \mathrm{Cl}_{L}$ )

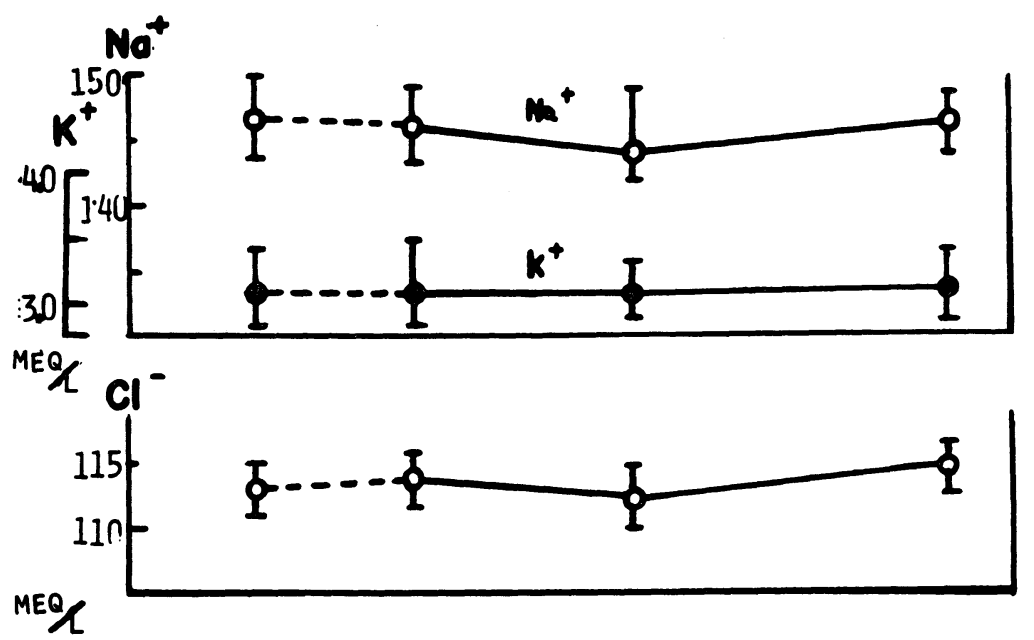

BODY WEIGHT AND ABDOMINAL GIRTH

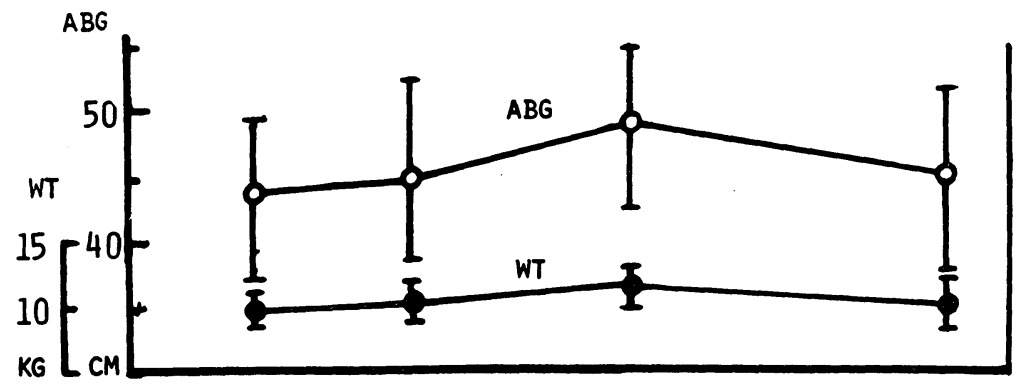

ALDOSTERONE

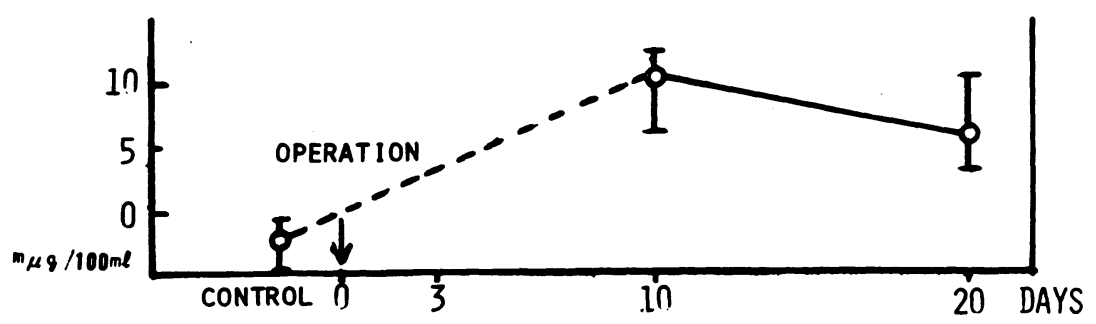

Fig. 3. Plasma electrolytes $\left(\mathrm{Na}^{+}, \mathrm{K}^{+}, \mathrm{Cl}^{-}\right)$, body weight, abdominal girth and aldosterone in Group 3. 
the following equation: $\mathrm{m} \mu \mathrm{g}$ of aldosterone measured $=0.255+0.926 \times \mathrm{m} \mu \mathrm{g}$ of aldosterone expected.

All values in the study were corrected for the mean blank of the method. The measurement values of plasma aldosterone in Groups 1, 2 and 3 are shown in Table 1. Liver function parameters are shown in Table 2. The Glutamic oxalacetic transaminase (G.O.T.) and glutamic pyruvic transaminase (G.P.T.) postoperative 20 days in Group 2 had a tendency of increase, as did the thymol turbidity test (T.T.T.) and the zinc sulfate test (Z.T.T.) too. Icterus index in Group 2 postoperative 20 days were higher when compared to those in Groups 1 and 3 ( $p<0.05$ ). Plasma albumin and cholinesterase postoperative 10 days and 20 days in Group 2 were lower than those in Group 1, especially, those of 20 days was significant statistically $(\mathrm{p}<0.05)$. Urea- $\mathrm{N}$ in Groups 2 and 3 were within normal limits.

The comparison of plasma electrolytes, body weight, abdominal girth, and aldosterone are shown in Figure 2 and 3. A direct correlation was found between levels in plasma aldosterone and the daily changes in abdominal girth and body weight. Electrolytes, especially plasma $\mathrm{Na}^{+}$in Group 2 decreased daily, and that of postoperative 20 days was lower compared to those in Group 1. On the other hand, it was found the values in Group 3 postoperative 20 days returned to within normal limits and this was associated with a reduction or diminution of ascites. Plasma $\mathrm{K}^{+}$in Groups 2 and 3 were within normal limits. The plasma aldosterone levels in Group 3 were significantly lower compared with those in Group $2(\mathrm{p}<0.01)$. This was especially true for the level 20 days after constriction of the thoracic inferior vena cava when the level in Group 3 was approximately one fifth of that in Group $2(\mathrm{p}<0.001)$.

\section{Discussion}

The biological activity of plasma aldosterone in closely related to its plasma concentration. Measurements of plasma aldosterone is therefore warranted and may be relevant when compared to urinary aldosterone levels which are affected by both hepatic or renal metabolism. In the experiments reported here, the techniques of Brodie and Shimizu et al. have been used and found to be an adequate and reliable method for the study of aldosterone in peripheral plasma. However, the method was slightly modified to eliminate the moist conditions which inhibit microacetylation. In the modified method, completely dehydrated solvents and apparatus are used, and a chamber which can maintain very low humidities was utilized. Confirmation of the 4- ${ }^{14} \mathrm{C}$-aldosterone- ${ }^{3} \mathrm{H}-21$-monoacetate product was obtained by $\mathrm{X}$-ray film radioautography as described above. Acetylation was carried out smoothly by the use of the ${ }^{3} \mathrm{H}$-acetic anhydride, specific activity $500 \mathrm{mCi} /$ mmole, and the $4-{ }^{14} \mathrm{C}$-aldosterone indicator $2 \mathrm{~m} \mu \mathrm{g}$, specific activity $56.7 \mathrm{mCi} / \mathrm{mmole}$ was used in the $15-30.39 \mathrm{~m} \mu \mathrm{g} / 100 \mathrm{~m} l$ measurement limit. As a result of these changes recovery is lower when compared with the original report of $22 \%$, probably because of the differences in apparatus, technique, isotopic batches and counting condition. However, the method has proved quite reliable in our hands.

The control values in Group 1 are lower than $1 \mathrm{~m} \mu \mathrm{g} / 100 \mathrm{~m} l$. These measurement values are lower than the $20-30 \mathrm{~m} \mu \mathrm{g} / 100 \mathrm{~m} l$ reported by Bojesen and Degn (1961), and the indirect measurement value of $2 \mathrm{~m} \mu \mathrm{g} / 100 \mathrm{~m} l$ reported by Ayres et al. (1962) who studied the disappearance of injected ${ }^{3} \mathrm{H}-\mathrm{d}, 1$,-aldosterone from the peripheral vein. Those animals used in these experiments, however, were sodium and potassium dieted, which may be the reason for the difference.

Plasma aldosterone postoperative 10 days and 20 days in Group 2 had a tendency of increase. Hyponatremia and impaired liver function were also observed. It is well known that the liver is the major site of aldosterone 
inactivation; this occurs mainly by saturation of double bonds and conjugation with glucuronic groups (Chart et al., 1956; Yates et al., 1958; Ayres et al., 1962; Appelgren and Marrero 1972). The concentration of plasma aldosterone is directly related to production rate and also related to metabolic clearance rate (Tait et al., 1962). The hepatic clearance of aldosterone can be calculated from the hepatic plasma flow and the hepatic extraction ratio of aldosterone. In our laboratory, the atrophy, degeneration and necrosis of the liver cells, and the deformity of mitochondria, the decrease of endoplasmic reticulum have been observed histologically and electronmicroscopically in animals with inferior vena caval constriction (Arima, 1972). Futher, the activity of the hepatic enzymes for the urea cycle and the uptake of ${ }^{3} \mathrm{H}$-uridine into intrahepatic cells have been proved to be decreased (Kawata, 1972; Ono, 1972). It seems probable therefore that inactivation of aldosterone is impaired in the liver with chronic passive venous congestion. In our laboratory, Sakoda (1964) has demonstrated that remarkable decrease of hepatic plasma flow in Group 2. Schneider et al. (1970) have suggested that the decrease in the hepatic clearance of aldosterone in the dogs with thoracic inferior vena caval constriction results entirely from the decrease in hepatic plasma flow. These observations suggest that the reduction in hepatic blood flow, liver cell's damage, and anoxia caused by chronic passive liver congestion, can lead to an increase in plasma aldosterone levels independent of changes that may be occurring in aldosterone secretion.

In spite of renal vein congestion caused by constriction of the thoracic inferior vena cava, the factor stopping the "Escape" and the feed back loop in the renin-angiotensinaldosterone system is required to maintain hyperaldosteronism in the dogs of constriction of the thoracic inferior vena cava, however its mechanism has never been clear. Blain et al. (1972) have suggested that the secretion of aldosterone in constriction of the thoracic inferior vena cava is markedly increased due to opening the feed back loop at a point where increase in extracelluar fluid volume can not be perceived by the receptors controlling the system.

Plasma aldosterone levels which increase after constriction of the thoracic inferior vena cava are lowered following portopulmonary shunt. The plasma aldosterone levels in Group 3 were significantly lower compared to those in Group 2. This was especially true for the level 20 days after constriction of the thoracic inferior vena cava when the level in Group 3 was approximately one fifth of that in Group 2. Ascites was well controlled.

Akita et al (1968) have demonstrated that the blood flow through the portopulmonary shunt measured by the use of ${ }^{85} \mathrm{Kr}$ was calculated as much as $19.2 \%$ in Group 3 type animals. Thus portopulmonary shunt improves the impaired hepatic hemodynamics, and alleviates the hepatic congestion caused by constriction of the thoracic inferior vena cava. And finally the fluid transudation from the hepatic and mesenteric lymph system into the abdominal cavity is reduced. Futher, the edema and the sequestration of the vein blood in the lower body are improved and the elevation of the renal vein pressure is decreased. These results possibly effect the hypoalbuminemia and hypovolemia found in Group 2 animals. The procedure therefore probably also leads to decreased aldosterone secretion mediated renin-angiotensin system, and activated aldosterone metabolism. These experiments show that the hyperaldosteronism which follows thoracic inferior vena caval constriction is significantly relieved by a portopulmonary shunt. Improvement of systemic and hepatic hemodynamics which alleviate hepatic congestion and hepatic dysfunction and allow aldosterone metabolism to proceed seems the most likely mechanism.

Our data support the clinical impression that splenopneumopexy is an effective prodedure to control the ascites associated with 
portal hypertension, especially in the BuddChiari syndrome.

\section{Acknowledgment}

Grateful acknowledgment is made to N. Shimizu M. D. for his advice in this investigation.

\section{References}

Akita, H. (1967). Geka 29, 583 (In Japanese). Akita, H., T. Katsuki, Y. Inoshima and S. Ishikawa (1968). Acta Med. Univ. Kagoshima. 10: Supp., 39.

Akita, H., K. Sakoda, Y. Nogami, S. Ishikawa, Y. Inamasu and Y. Inoshima (1967). Acta Med. Univ. Kagoshima. 9, 233.

Akita, H. and M. Tabuchi (1958). Japanese Journal of Gastroenterology 55, 568. (In Japanese).

Appelgren, L. E. and E. Marrero (1972). Acta Pharmacol. Toxicol. 31, 86.

Arima, Y. (1972). Med. J. Kagoshima Univ. 24, 95. (In Japanese).

Ayres, C. R., J. O. Davis, F. Liebman, C. C. J. Carpenter and M. Berman (1962). J. Clin. Invest. 41, 884.

Bartter, F. C., G. W. Liddle, L. E. Jr. Duncan, J. K. Barber and C. Dela (1956). Ibid. 35, 1306.

Bayard, F., I. Z. Beitins, A. Kowarski and C. J. Migeon (1970). J. Clin. Endocrinol. and Metabolism 31, 1.

Blaine, E. H., J. O. Davis and P. D. Harris (1972). Circulation Research 30, 713.

Blair-West, J. R., J. P. Coghlan, D. A. Deton, J. R. Goding, M. Wintour and R. D. Wright (1963). Recent Progress in Hormon Research 19, 311.
Bojesen, E. and H. Degn (1961). Nature 190, 352.

Brodie, A. H., N. Shimizu, S. A. S. Tait and J. F. Tait (1967). J. Clin. Endocrinol. and Metabolism 27, 997.

Chart, J. J., E. S. Goldon, P. Helmer and M. Lesher (1956). J. Clin. Invest. 35, 254.

Coghlan, J. P. and B. A. Scoggins (1967). J. Clin. Endocrinol. and Metabolism 27, 1470.

Conn, J. W. (1955). J. Lab. Clin. Med. 45, 3.

Davis, J. O., M. J. Olichney, T. C. Brown and P. F. Binnion (1965). J. Clin. Invest. 44, 1433.

Ito, T., J. Woo, J. Haning and R. Horton (1972). J. Clin. Endocrinol. and Metabolism 34, 106.

Kawata, T. (1972). Med. J. Kagoshima Univ. 24, 51. (In Japanese).

Kliman, B. and R. E. Peterson (1960). J. Biol. Chem. 235, 1639.

Llaurado, J. G. and M. F. A. Woodruff (1957). Surgery 42, 313.

Ono, J. (1972). Acta Med. Univ. Kagoshima. 14, 157.

Orloff, M. J., C. A. Lipman, S. M. Noel, N. A. Halasz and T. Neesby (1965). Surgery 58, 225.

Sakoda, K. (1964). Med. J. Kagoshima Univ. 16, 55. (In Japanese).

Schneider, E. G., J. O. Davis, J. S. Baumber and A. J. Johnson (1970). Circulation Research 26, I-177.

Simpson, S. A., J. F. Tait, A. Wettstein, R. Neher, J. V. E. O. Schindler and T. Reichstein (1954). Experientia 15, 132.

Tait, J. F., B. Little, S. A. S. Tait and C. Flood (1962). J. Clin. Invest. 41, 2093.

Wolff, H. P., D. Lommer and M. Torbica (1965). Schweiz. med. Wochschr. 95, 387.

Yates, F. E., J. Urguhart and A. L. Herbest (1958). Am. J. Physiol. 194, 65. 